\title{
Multi modal imaging in corneal edema after corneal collagen cross-linking (CXL); a case-based literature review
}

\author{
Mohammad Soleimani ${ }^{1}$, Zohre Ebrahimi ${ }^{1}$, Mohammad Yazdani Moghadam ', Mansoor Shahriari², \\ Sara Behzadfar ${ }^{3}$, Bahareh Ramezani ${ }^{3}$ and Kasra Cheraqpour ${ }^{1 *}$ (D)
}

\begin{abstract}
Background: Keratoconus (KCN) is a common ectatic disorder of the cornea. Corneal collagen cross-linking (CXL) is used as an effective option to slowdown the disease progression. Although CXL is considered a safe procedure, corneal endothelial damage, especially in corneal thickness of less than $400 \mu \mathrm{m}$, has been reported.

Case presentation: A 25-year-old man known case of KCN was referred with complaints about blurred vision and discomfort of the right eye 3 days after performing CXL. The preoperative thinnest point was $461 \mu \mathrm{m}$. His presenting BCVA was CF at $1 \mathrm{~m}$. Examination showed central corneal edema and stromal haziness. ASOCT demonstrated increased central corneal thickness and very deep CXL line. In the confocal scan, anterior stroma showed hyper-reflective lines without recognizable cells and nerves, the middle stroma showed rare active and edematous keratocytes and a hyper-reflective reticular pattern with elongated keratocytes and needle-like structures involving the posterior stroma indicated increased depth of CXL. To manage the patient, debridement of loosened epithelium was done. Non-preservative steroid 1\% eye drop was prescribed frequently. The corneal edema was completely resolved during 2 months with no need for surgical procedure and BCVA of 20/30 in his right eye.

Conclusion: The corneal thickness of more than $400 \mu \mathrm{m}$ cannot guarantee the absence of corneal edema after corneal collagen cross-linking, which can pertain to several factors such as inadvertently using of higher energy as well as the incorrect observance of all guidelines, instructions, and other precautions, even by a trained surgeon.
\end{abstract}

Keywords: Corneal edema, Collagen cross-linking, CXL, Review, Keratoconus

\section{Background}

Keratoconus $(\mathrm{KCN})$ is a common ectatic disorder of the cornea with clinical pictures of progressive stromal thinning and highly irregular astigmatism leading to significant visual disturbance [1]. Nowadays, corneal collagen cross-linking $(\mathrm{CXL})$ is used as an effective option to slow the disease progression. In this technique, riboflavin sensitivity to ultraviolet radiation strengthens the corneal

\footnotetext{
*Correspondence: Cheraqpourk@gmail.com

${ }^{1}$ Eye Research Center, Farabi Eye Hospital, Tehran University of Medical Sciences, Tehran 1336616351, Iran
}

Full list of author information is available at the end of the article biomechanic through providing additional cross-links between collagen fibers. These interactions can enhance the stiffness of corneal collagens and increase resistance against keratectasia [2,3]. CXL is a highly safe procedure in the condition of adherence to standard protocols. However, several complications have been reported, which include persistent corneal haziness, infectious keratitis, and corneal endothelial cell damage, particularly at the corneal thickness of less than $400 \mu \mathrm{m}$ [4].

Herein, we report a case of post CXL corneal edema in a patient who interestingly had preoperative corneal thickness of $461 \mu \mathrm{m}$. Also, we discuss findings of original author(s) and the source, provide a link to the Creative Commons licence, and indicate if changes were made. The images or other third party material in this article are included in the article's Creative Commons licence, unless indicated otherwise in a credit line to the material. If material is not included in the article's Creative Commons licence and your intended use is not permitted by statutory regulation or exceeds the permitted use, you will need to obtain permission directly from the copyright holder. To view a copy of this licence, visit http://creativecommons.org/licenses/by/4.0/. The Creative Commons Public Domain Dedication waiver (http://creativeco mmons.org/publicdomain/zero/1.0/) applies to the data made available in this article, unless otherwise stated in a credit line to the data. 
multimodal imaging of our case and, finally, provide a brief review on similar reported studies.

\section{Case presentation}

A 25-year-old man was referred with complaints about blurred vision and discomfort of the right eye 3 days after performing CXL in another ophthalmic center. He was a known case of KCN. Serial preoperative Scheimpflug tomography images indicated the progressive $\mathrm{KCN}$. Also, the thinnest point of the right cornea was $461 \mu \mathrm{m}$, which allowed planning for the CXL procedure (Fig. 1). According to the patient's medical records and through a phone call to his surgeon, preservative free $0.1 \%$ riboflavin solution with $20 \%$ dextran (Sina Darou, Iran) was administered every $3 \mathrm{~min}$ for $30 \mathrm{~min}$ after central $8-\mathrm{mm}$ epithelial debridement. However, a crater or container was not used to keep the riboflavin in touch with the cornea. Then, this central part of the cornea was irradiated with UV-A light (IROC, Zürich, Switzerland) with the wavelength of $370 \mathrm{~nm}$ and radiation of $3.0 \mathrm{~mW} / \mathrm{cm}^{2}$ after proper calibration. Riboflavin solutions were applied to the cornea every 5 min during the final $30 \mathrm{~min}$ of the procedure. Finally, a therapeutic contact lens was applied.

The patient developed corneal edema within the first day of procedure which did not resolve until the 3rd day of follow-up visit. Hence, the patient was referred to our center. He was suffering from pain and photophobia. Congestion, central corneal edema, and stromal haziness were noted on the slit-lamp examination (Fig. 2a). The therapeutic contact lens was in place. The crystalline lens was clear and the fundus examination was normal. The best-corrected visual acuity (BCVA) and manifest refraction of the right and the left eyes were counting fingers at $1 \mathrm{~m}\left(-3.00-3.75 \times 160^{\circ}\right)$ and $20 / 20\left(-2.00-0.25 \times 47^{\circ}\right)$, respectively. Furthermore, the intraocular pressure (IOP) of the right and the left eyes were $12 \mathrm{mmHg}$ and $14 \mathrm{mmHg}$, respectively.

Different imaging modalities were applied. ASOCT (Optovue RTVue device, CA, USA) demonstrated increased central and paracentral corneal thickness $(673 \mu \mathrm{m}$ in the central part) with full-thickness stromal haziness. Moreover, no obvious Descemet rupture was detected. Demarcation line of CXL was visible as a

OCULUS - PENTACAM 4 Maps Chamber

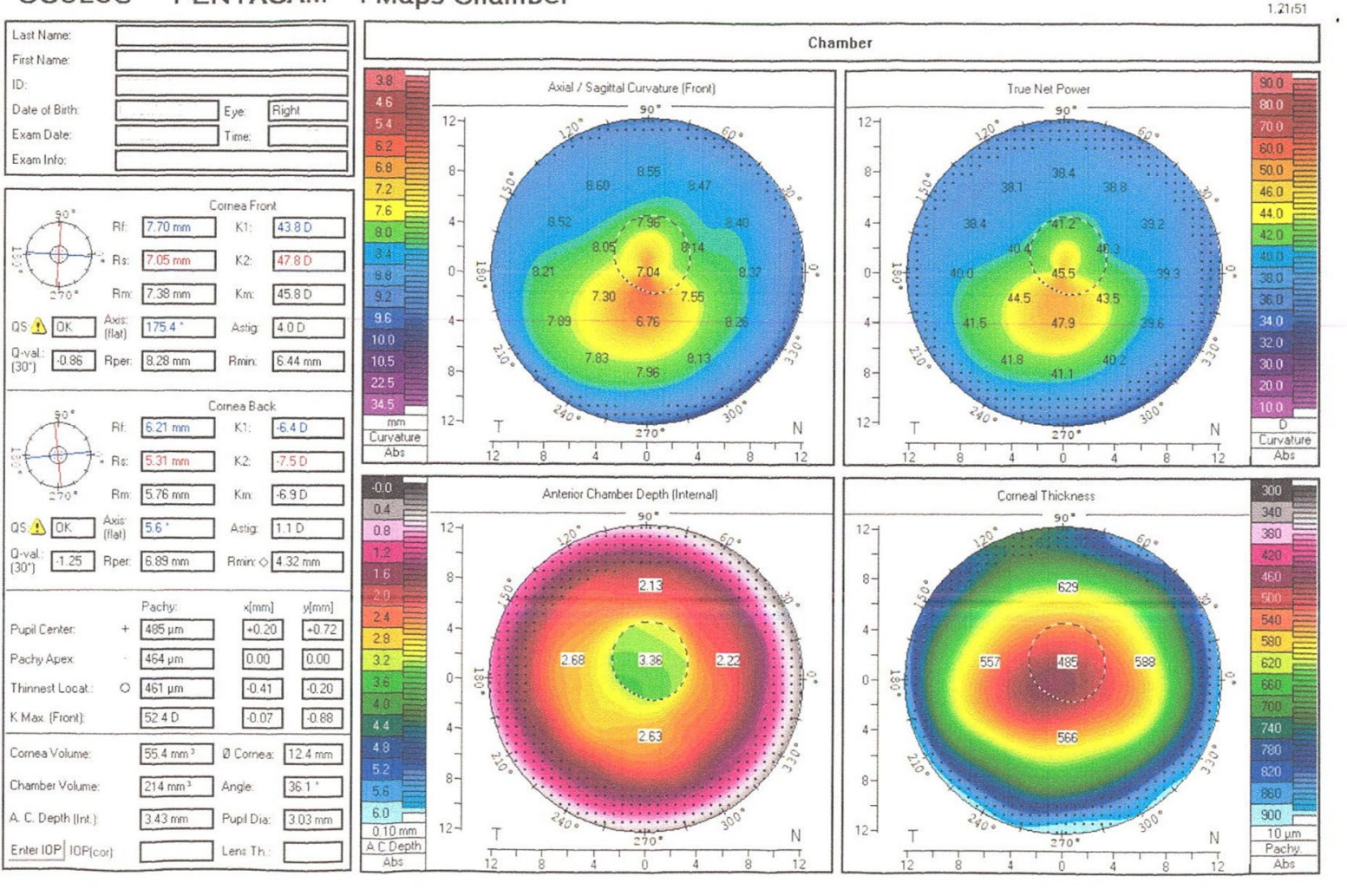

Fig. 1 Preoperative Pentacam of the patient's right eye 


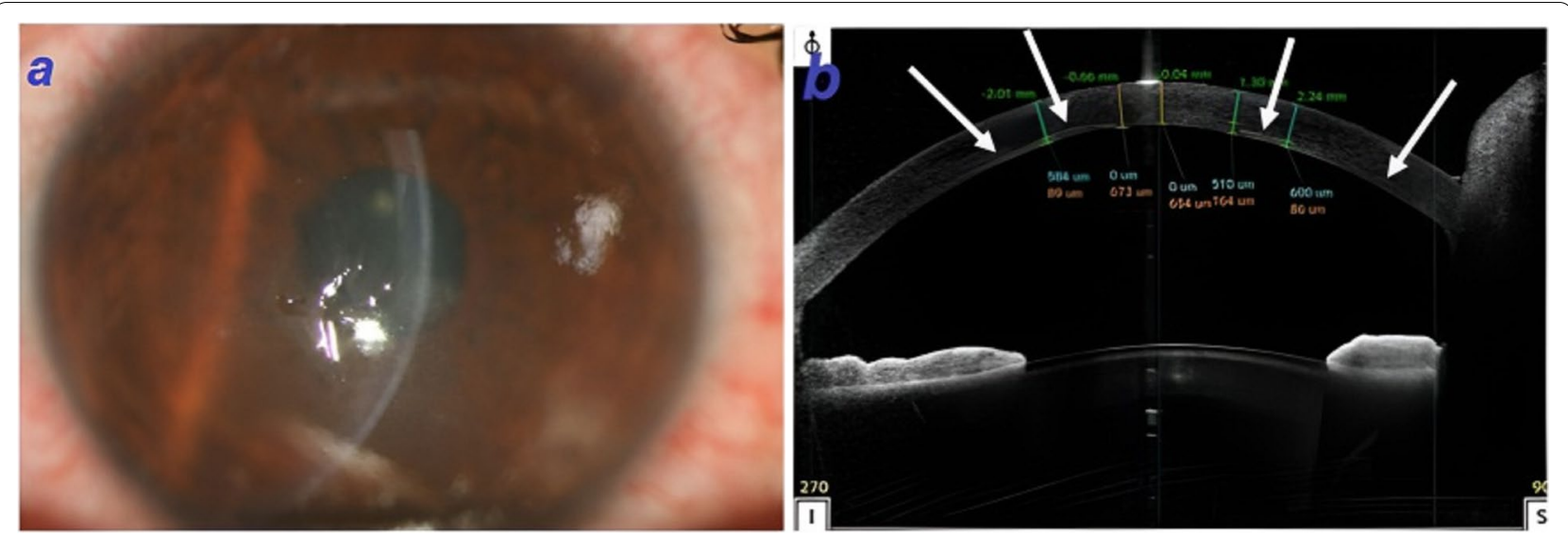

Fig. 2 a Slit photograph of the right eye after CXL illustrates corneal edema and epithelial defect. b ASOCT of the right eye indicating increased thickness of cornea (white arrows are representative for faint demarcation line)

faint hyper-reflective line between corneal stroma and endothelium in the paracentral area and beneath the endothelial layer in the center of the cornea showing a very deep CXL line (Fig. 2b).

Although applying specular microscopy was not possible due to severe corneal edema, confocal scanning estimated the number of endothelial cells up to 1867 cells/ $\mathrm{m} 2$ (Fig. 3a). It should be mentioned specular microscopy (SP 3000P; Topcon, Japan) done 1 month later when the cornea turned clear and revealed the cell density of 1909 cells / 2 (Table 1 ).

The confocal microscopy examination was performed for evaluating the effect of CXL on the different layers including anterior, middle, and posterior stroma, as well as endothelial layer. Anterior stroma showed hyperreflective lines without recognizable cells and nerve fibers. In the middle stroma, rare active and edematous keratocytes were found. The boundary of the cross-sectional area was determined by a hyper-reflective reticular pattern with elongated keratocytes and needle-like structures that involved the posterior stroma, indicating the increased depth of the affected region of the CXL (Fig. 3).

To manage the patient, the bandage contact lens was removed followed by debridement of loosened epithelium for better re-epithelialization and substituted with new contact lens (FREQUENCY ${ }^{\circledR} 55$ soft contact lens with base curvature of $8.7 \mathrm{~mm}$, diameter of $14.4 \mathrm{~mm}$, and power of -0.25 diopter). Non-preservative steroid $1 \%$ (NPS1\%) eye drop was prescribed for every $2 \mathrm{~h}$ and homatropine $2 \%$ eye drop was used twice a day. On the 4th day of follow-up visit (7 days after CXL) re-epithelialization of the cornea was obviously accompanied by reduced edema and haziness (Fig. 4a). The corneal edema slowly reduced and completely resolved with no need for surgical procedures during 2 months. The stromal haze was partially resolved within 3 months with a residual whorl-shaped corneal scar (Fig. 4b). Steroids eye drops were tapered and discontinued in 3 months. Topographic evaluation was stable without any signs of progression. Finally, the patient obtained the BCVA of 20/30 in his right eye. It could be mentioned the preoperative refraction and BCVA were $-3.50-4.00 \times 160^{\circ}$ and $20 / 25$, respectively.

\section{Discussion and conclusions}

Corneal collagen cross-linking is considered a favorable treatment option to slowdown the progression of keratoconus. This method is considered highly safe without significant damages to the endothelium or inner structures of the eye such as crystalline lens and retina in terms of adherence to standard protocols, indications, and contraindications. It has been shown that keratocyte loss within $300 \mu \mathrm{m}$ of the stroma occurs immediately after the procedure, which takes about 6 months until repopulation [5].

The cytotoxic effect of riboflavin/UV-A combination on corneal endothelium has been revealed previously [6]. It seems human corneal endothelial cells are much more resistant to riboflavin-enhanced UV-A radiation than the animal corneal endothelial cells [7]. This finding may be related to the presence of collagen fibers which act as a protective factor. Moreover, thickness of $400 \mu \mathrm{m}$ for saturation with riboflavin reduces the amount of radiation to the endothelial cells into level of $0.18 \mathrm{~mW} / \mathrm{cm}^{2}$, which is half of the required level for cytotoxic effect $(0.36 \mathrm{~mW} /$ $\mathrm{cm}^{2}\left(0.65 \mathrm{~J} / \mathrm{cm}^{2}\right)$ [5]. Hence, the corneal thickness of less than $400 \mu \mathrm{m}$ has been identified as the most important risk factor for developing post CXL endothelial cell damage [6]. 

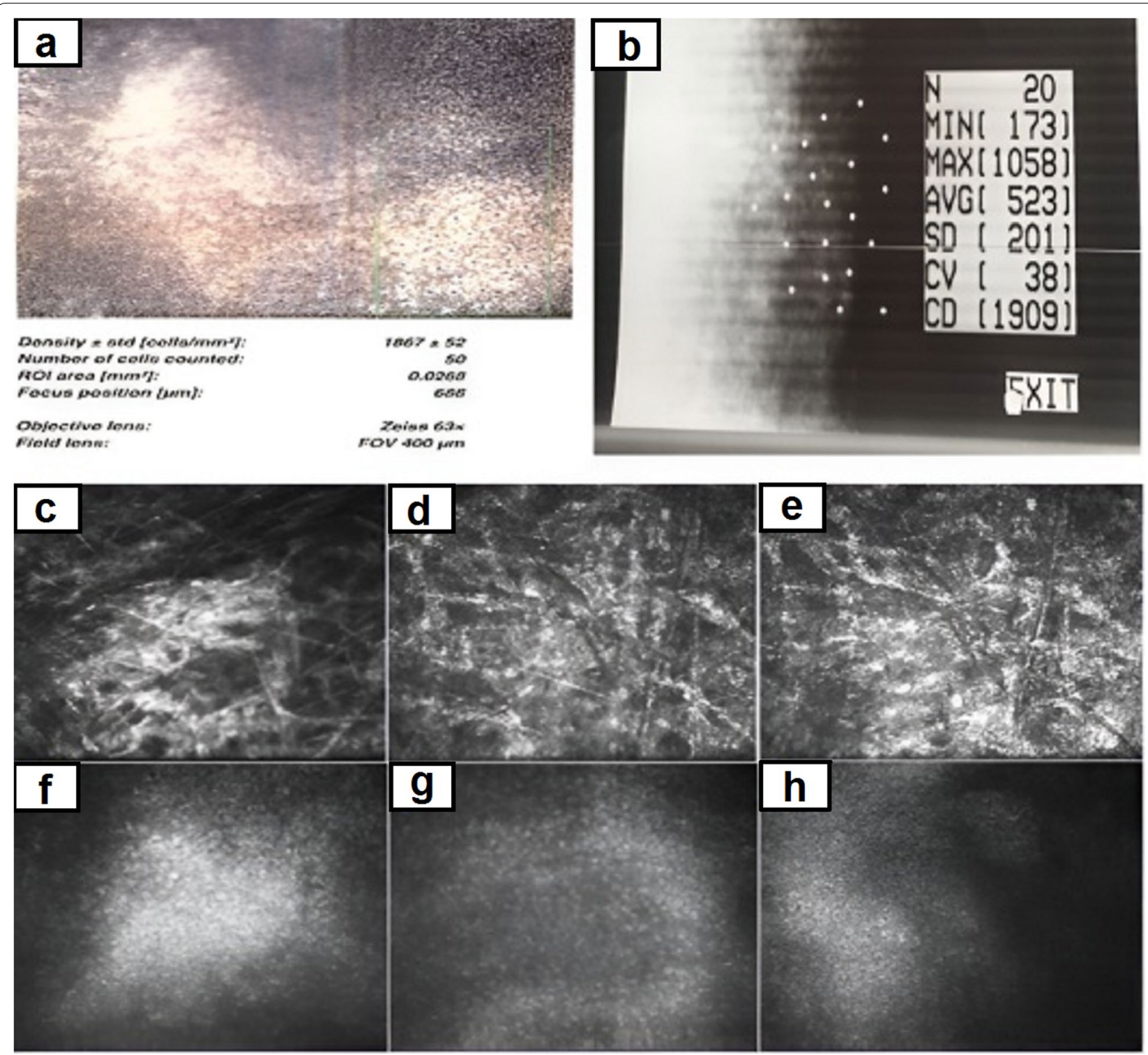

Fig. 3 a Confocal scanning of the right eye estimated the number of corneal cells of about 1867 cells. b Specular microscopy of the right eye one month after treatment. c Confocal scan of the anterior stroma. $\mathbf{d}$ Confocal scan of the middle stroma. e Confocal scan of the posterior stroma. $\mathbf{f}, \mathbf{g}$, and $\mathbf{h}$. Confocal scan of the endothelium

Table 1 Comparison of specular microscopy indexes between two eyes after resolving corneal edema

\begin{tabular}{lll}
\hline & Right eye (treated) & $\begin{array}{l}\text { Left eye } \\
\text { (untreated) }\end{array}$ \\
\hline MIN & 173 & 189 \\
MAX & 1058 & 378 \\
AVG & 523 & 315 \\
CV & 38 & 26 \\
CD & 1909 & 3207 \\
\hline
\end{tabular}

MIN Minimum cell size, MAX Maximum cell size, AVG Average cell area, CV Coefficient of variation, $C D$ Cell density
Several factors have been introduced that might play a role in endothelial damage including inadvertent delivery of excessive energy due to poor calibration and focusing, intraoperative corneal thinning secondary to dehydration caused by epithelium removal or application of dextran containing riboflavin drops, inaccurate pachymetry reading during surgery, acute hydrops, pre-existing Fuchs endothelial dystrophy, extreme intra-CXL treatment of corneal thinning occurring during CXL, and endothelial cell damage due to waterjet wave during intraoperative irrigation procedure [8]. Also, herpetic disciform edema 

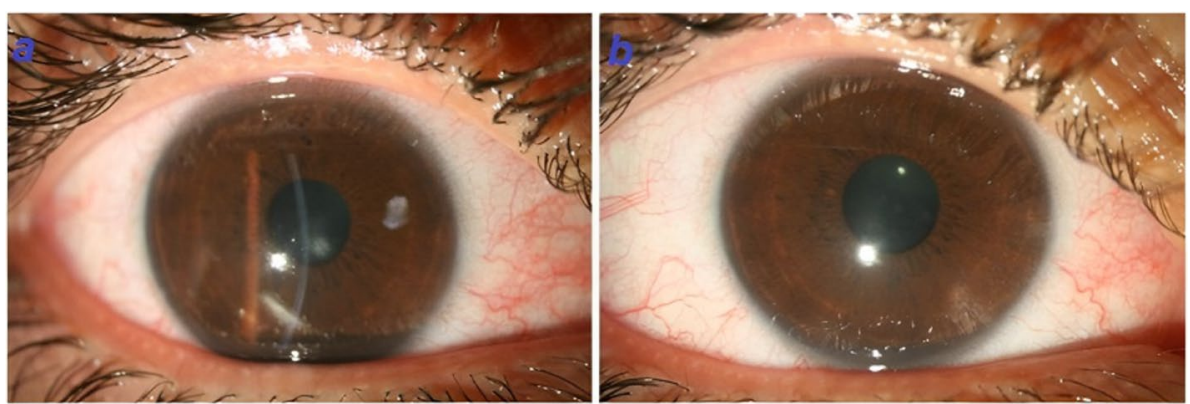

Fig. 4 a. 4 days after treatment, epithelialization occurred and stromal edema reduced. b. Two months after treatment

and noninfectious endotheliitis caused by direct injury to the endothelial cells by UV-A are the other possibilities [9]. However, clinical and imaging findings of our case were not compatible with those of the two latter differential diagnoses. To the best of the author's knowledge, only 4 reports (containing 13 cases) of post CXL corneal edema are available on the Pubmed/Medline database, as summarized in Table 2.

Our case developed corneal edema immediately after the procedure which completely was resolved within further follow-up visits. Multimodal imaging such as confocal microscopy, specular microscopy, and ASOCT was performed to evaluate corneal edema. Confocal microscopy revealed the corneal endothelial cell density of about 1860 cells which was $60 \%$ of cell density of the untreated fellow eye (Table 1). Furthermore, specular microscopy after clearing the corneal edema showed decreased number of endothelial cells, polymorphism, and polymegatism considered as other witnesses of endothelial cell damage during this procedure. However, endothelial cells count before CXL was unknown, but based on medical records and the referring surgeon's claim, preoperative clinical examination did not reveal any endothelial abnormalities.

The ASOCT showed an increase in the depth of crosslinking, in which the demarcation line was observed in the posterior part of the stroma and the center area on the endothelium. However, it normally should be detected between the anterior third and posterior twothird of the stroma. Other causes of corneal edema such as acute hydrops and rupture of the Descemet membrane were ruled out by this imaging.

In addition to decrease in the number of endothelial cells in the acute phase, confocal microscopy showed the effects of cross-linking in the form of hyper-reflective lines with a reticular pattern at posterior stroma and endothelium (depth of $456 \mu \mathrm{m}$ ), which was another confirmation of the increase in cross-linking depth. Also, it seems needle-like structures are representative for new synthesized collagen produced by activated keratocytes at the transition zone [12]. Although the referring surgeon insisted on following the standard protocols, an error in performing cross-linking can be considered as one of the possible causes for this complication. Furthermore, it seems one of the pitfalls in the management of this patient is lack of intraoperative pachymetry since it has been shown remarkable alteration in pachymetry is not an uncommon event during CXL.

Improper focus or calibration of the ultraviolet light source and closer position of the eye in machines using only one light-emitting diode (LED) as the UV-A source can cause delivery of higher energies and subsequent cytotoxic damages to the corneal endothelium. Moreover, the presence of intact film of riboflavin during the procedure is so important. On the one side, riboflavin acts as a photosensitizer increasing the absorption of UV, which results in collagen cross-linking. On the other side, riboflavin has a protective role blocking the delivery of high energy to inner structures like endothelium. Moreover, continuity in providing riboflavin prevents from dehydration and subsequent corneal thinning [10]. It has been reported dextran-riboflavin solution can lead to about $10 \%$ corneal thinning [13]. So, frequent instillation of this agent during the procedure should be considered.

Beside the corneal thickness, proper calibration and focusing, removal of the lid speculum during instillation of riboflavin drops to prevent excessive thinning secondary to evaporation, providing intact continuous film of riboflavin, transepithelial CXL, accelerated CXL, and frequent intratreatment checks of the corneal thickness with re-administration of hypotonic solution if the thickness drops to less than $350 \mu \mathrm{m}$ are the considerable factors for preventing from collateral damages to other structures of the eye such as endothelium [14].

In conclusion, our case highlights that the corneal thickness of more than $400 \mu \mathrm{m}$ cannot guarantee the absence of corneal edema after corneal collagen crosslinking, which can pertain to several factors such as 


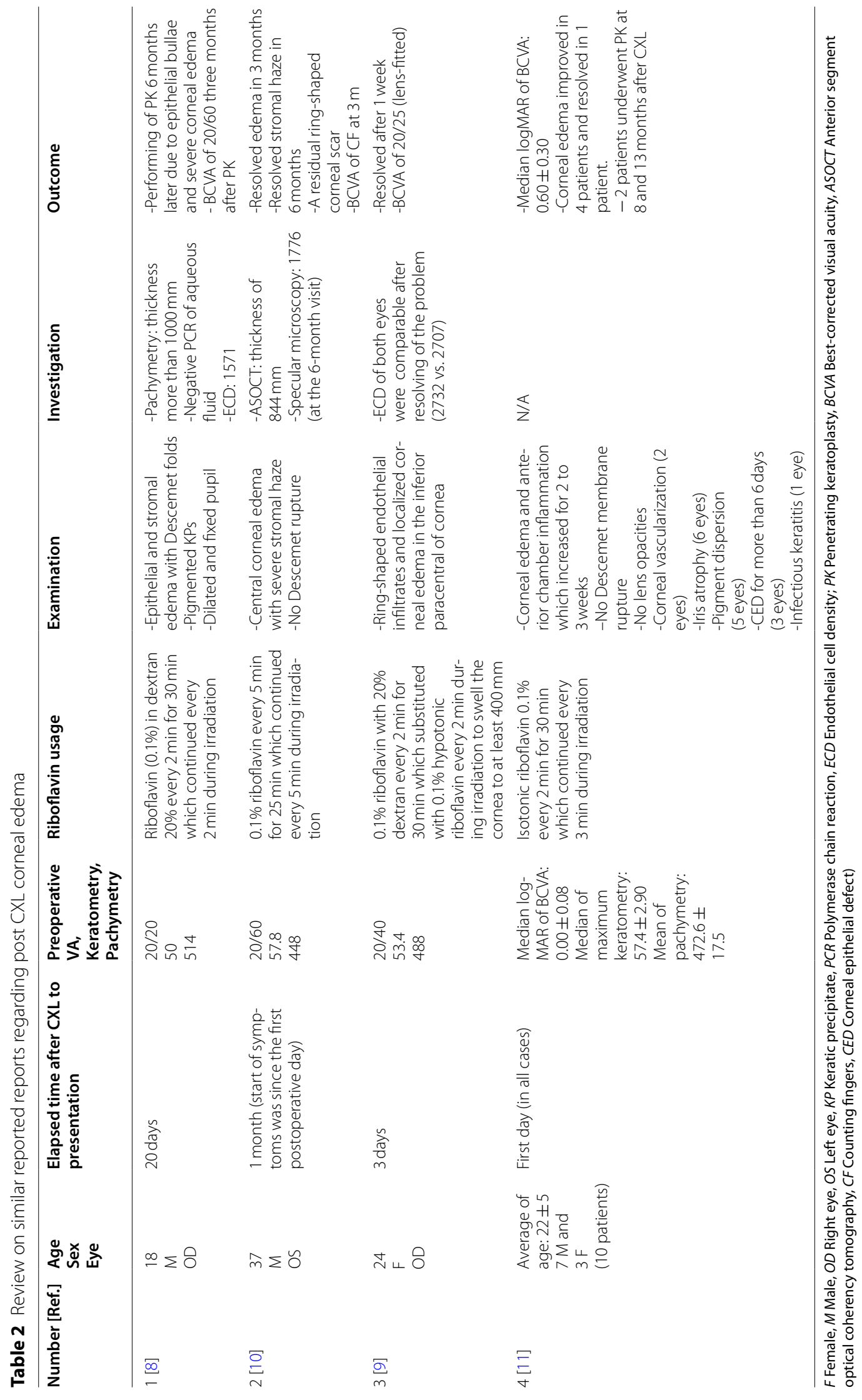


inadvertently using higher energy due to improper calibration or focus as well as the incorrect observance of all guidelines, instructions, and other precautions, even by a trained surgeon.

\section{Abbreviations}

KCN: Keratoconus; CXL: Corneal collagen cross-linking; CCT: Central corneal thickness; BCVA: Best-corrected visual acuity; UV: Ultra violet; NPS: Non-preservative steroid; LED: Light-emitting diode.

\section{Acknowledgements}

N/A

\section{Authors' contributions}

MS1 visited the patient, performed the treatment, and collected the patient information. MS1 conceptualized the report. MS1, ZE, MYM, and KC wrote the manuscript. KC, MS2, SB, and BR performed critical revisions on the manuscript. All the authors read and approved the final manuscript.

\section{Funding}

N/A

\section{Availability of data and materials}

The data are available from the corresponding author on reasonable request.

\section{Declarations}

\section{Ethics approval and consent to participate}

This study adhered to the tenets of Declaration of Helsinki. Ethics committee approval was not required for this case report.

\section{Consent for publication}

We obtained written consent for publication from the patient for publishing this case report.

\section{Competing interests}

The authors declare no potential conflicts of interest.

\section{Author details}

${ }^{1}$ Eye Research Center, Farabi Eye Hospital, Tehran University of Medical Sciences, Tehran 1336616351, Iran. ${ }^{2}$ Imam Hossein Medical Center, Shahid Beheshti University of Medical Sciences, Tehran, Iran. ${ }^{3}$ School of Medicine, Iran University of Medical Sciences, Tehran, Iran.

Received: 5 April 2021 Accepted: 15 December 2021

Published online: 24 December 2021

\section{References}

1. Sahebjada S, Xie J, Chan E, Snibson G, Daniel M, Baird PN. Assessment of anterior segment parameters of keratoconus eyes in an Australian population. Optom Vis Sci. 2014:91(7):803-9.

2. Mejía LF, Santamaría JP, Acosta C. Symptomatic management of postoperative bullous keratopathy with nonpreserved human amniotic membrane. Cornea. 2002;21(4):342-5.

3. Wollensak G, Spoerl E, Seiler T. Riboflavin/ultraviolet-A-induced collagen crosslinking for the treatment of keratoconus. Am J Ophthalmol. 2003;135(5):620-7.

4. Koller T, Mrochen M, Seiler T. Complication and failure rates after corneal crosslinking. J Cataract Refract Surg. 2009;35(8):1358-62.

5. Spoerl E, Mrochen M, Sliney D, Trokel S, Seiler T. Safety of UVA-riboflavin cross-linking of the cornea. Cornea. 2007;26(4):385-9.

6. Wollensak G, Spoerl E, Wilsch M, Seiler T. Endothelial cell damage after riboflavin-ultraviolet-a treatment in the rabbit. J Cataract Refract Surg 2003;29(9):1786-90
7. Mooren P, Gobin L, Bostan N, Wouters K, Zakaria N, Mathysen DG, et al. Evaluation of UVA cytotoxicity for human endothelium in an ex vivo corneal cross-linking experimental setting. J Refract Surg. 2016;32(1):41-6.

8. Bagga B, Pahuja S, Murthy S, Sangwan VS. Endothelial failure after collagen cross-linking with riboflavin and UV-A: case report with literature review. Cornea. 2012;31(10):1197-200

9. Gumus K. Acute idiopathic endotheliitis early after corneal cross-linking with riboflavin and ultraviolet-a. Cornea. 2014;33(6):630-3.

10. Gokhale NS. Corneal endothelial damage after collagen cross-linking treatment. Cornea. 2011;30(12):1495-8.

11. Sharma A, Nottage JM, Mirchia K, Sharma R, Mohan K, Nirankari VS. Persistent corneal edema after collagen cross-linking for keratoconus. Am J Ophthalmol. 2012;154(6):922-926. e921.

12. Jordan C, Patel DV, Abeysekera N, McGhee CN. In vivo confocal microscopy analyses of corneal microstructural changes in a prospective study of collagen cross-linking in keratoconus. Ophthalmology. 2014;121(2):469-74

13. Wollensak $G$, Aurich $H$, Wirbelauer $C$, Sel S. Significance of the riboflavin film in corneal collagen crosslinking. J Cataract Refract Surg. 2010;36(1):114-20.

14. Gatzioufas Z, Richoz O, Spoerl E, Hafezi F. Persistent corneal edema after collagen cross-linking for keratoconus. Am J Ophthalmol. 2013;155(3):610-1.

\section{Publisher's Note}

Springer Nature remains neutral with regard to jurisdictional claims in published maps and institutional affiliations.
Ready to submit your research? Choose BMC and benefit from:

- fast, convenient online submission

- thorough peer review by experienced researchers in your field

- rapid publication on acceptance

- support for research data, including large and complex data types

- gold Open Access which fosters wider collaboration and increased citations

- maximum visibility for your research: over $100 \mathrm{M}$ website views per year

At BMC, research is always in progress.

Learn more biomedcentral.com/submissions 